Fanum

Sociológico
Forum Sociológico

Série II

21 | 2011

Transformação urbana

\title{
Spotcity: a arte e a política do espaço público
}

\author{
Catharina Thörn
}

Tradutor: Leonor Machado

\section{CpenEdition}

\section{Journals}

\section{Edição electrónica}

URL: https://journals.openedition.org/sociologico/435

DOI: $10.4000 /$ sociologico.435

ISSN: 2182-7427

\section{Editora}

CICS.NOVA - Centro Interdisciplinar de Ciências Sociais da Universidade Nova de Lisboa

\section{Edição impressa}

Data de publição: 1 dezembro 2011

Paginação: 43-53

ISSN: 0872-8380

\section{Refêrencia eletrónica}

Catharina Thörn, «Spotcity: a arte e a política do espaço público», Forum Sociológico [Online], 21 | 2011 , posto online no dia 05 setembro 2012, consultado o 30 março 2022. URL: http://

journals.openedition.org/sociologico/435 ; DOI: https://doi.org/10.4000/sociologico.435

Este documento foi criado de forma automática no dia 30 março 2022

(c) CICS.NOVA 


\title{
Spotcity: a arte e a política do espaço público
}

\author{
Catharina Thörn \\ Tradução : Leonor Machado
}

\section{Arte e espaço público}

1 Em Setembro de 2007, em Gotemburgo, Suécia, o artista Tomas Ferm apropriou-se de um parque público, entre eléctricos, autocarros e centros comerciais e transformou-o num centro cultural ao ar livre com um palco, um quiosque de arte e um contentor destinado à exibição de filmes. O parque chama-se Brunnsparken e está localizado no coração de Gotemburgo. O parque é sobretudo utilizado como um espaço de passagem das pessoas que circulam em Gotemburgo. É também um dos últimos lugares que restam no centro da cidade onde deambulam pessoas que não têm para onde ir, tais como os sem-abrigo e os jovens. Tornou-se, assim, um espaço estigmatizado. Tomas Ferm permaneceu durante três semanas no Brunnsparken e transformou este local de passagem e estigmatizado num lugar com animação onde as pessoas se reuniam para assistir a actuações e para tomar parte em discussões. No sítio da internet da SpotCity, Tomas Ferm explicou quais as suas intenções em relação a este projecto:

Enquanto em todas as cidades do mundo o espaço público se reduz, o espaço privado expande-se. A SpotCity cria um local para a arte, cultura e debate dentro do centro da cidade de Gotemburgo com o objectivo de encetar uma discussão: Que tipo de cidade queremos? Será que a arte pode fazer a diferença? Como é usado o espaço público e como é que pode vir a ser usado no futuro?

(www.spotcity.se [10/9-08])

2 A SpotCity caracterizou-se por uma forte convicção de que a arte e a cultura podem contribuir para a discussão contínua sobre o desenvolvimento da cidade. Desde há muitas décadas que o papel da arte pública tem vindo a ser examinado em pormenor e muitos têm questionado a forma como tem sido usada pelas entidades públicas. Quando Rosalyn Deutsche no seu livro clássico, Evictions, faz a análise da arte pública e da revitalização de Nova Iorque, refere que: 
Como prática corrente nas áreas edificadas, a arte pública contribui para a produção de significados, utilizações e formas na cidade. Neste papel, pode servir para garantir a aprovação para a reconversão e reestruturação que compõem a forma histórica da última urbanização capitalista. Mas, tal como outras instituições, pode também questionar e resistir a esses processos, revelando as supostas contradições do processo urbano. (Deutsche, 1998: 164.)

Mais recentemente, o grupo de pesquisas arquitectónicas BAVO criticou os artistas contemporâneos por se converterem à prática de "Arte-ONG". Querem com isto dizer arte que "esteticiza" a injustiça social e elimina conflitos. A BAVO argumenta que os urbanistas e os promotores pedem aos artistas para desenvolverem micro-soluções criativas para a resolução de problemas sociais estruturais e para fornecerem ferramentas e manuais de "faça você mesmo" com vista à intervenção na renovação urbana. Com efeito, a BAVO afirma que os artistas passaram a estar tão perto do poder que se tornaram o equivalente cultural dos jornalistas instalados na Guerra do Iraque. E, em Novembro de 2009, alguns artistas de Hamburgo redigiram o manifesto Not in our name ("Não em nosso nome"), argumentando que nunca mais participariam em estratégias culturais de branding da cidade, escrevendo no manifesto:

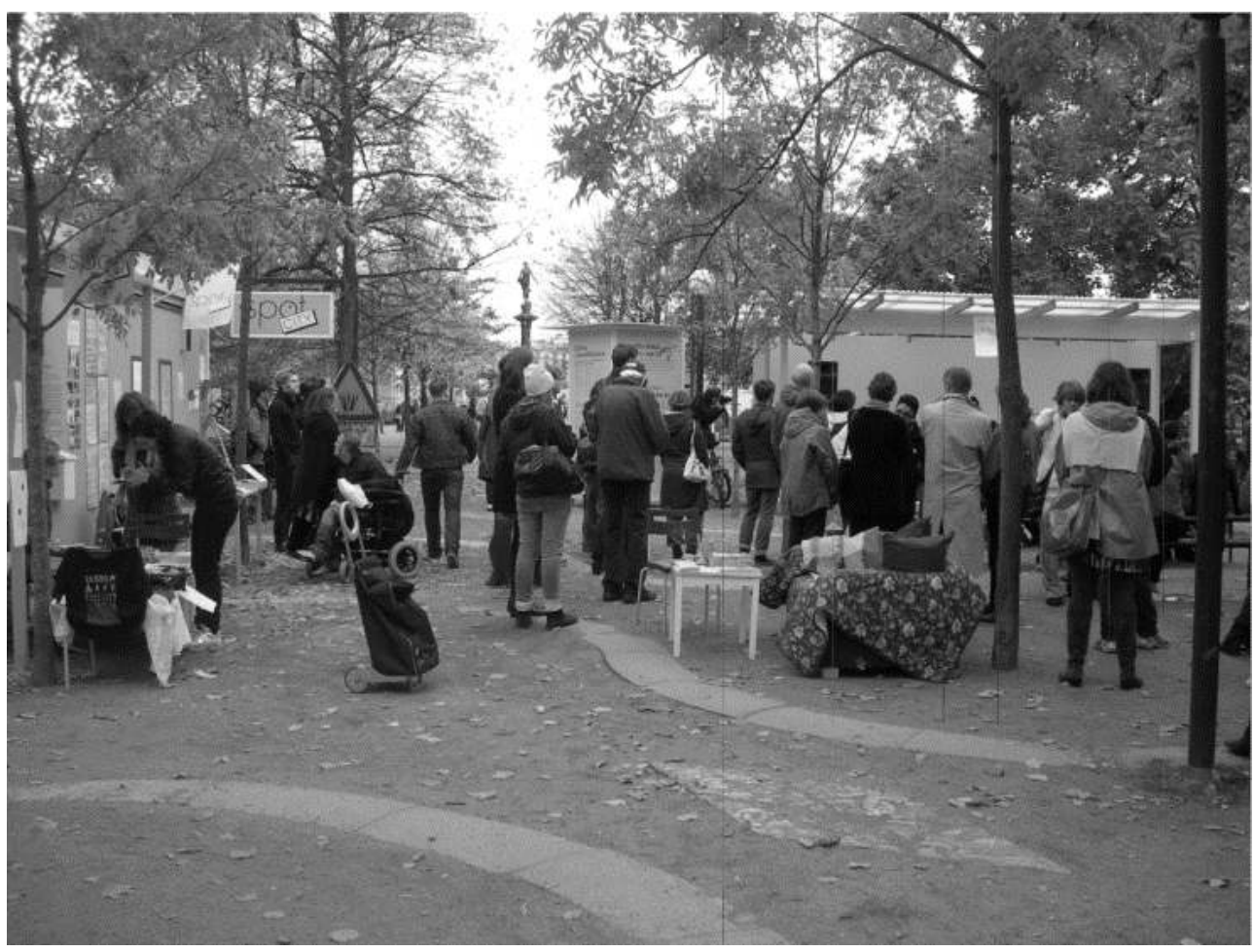

Pessoas juntando-se na SpotCity

4 Afirmamos: A cidade não é uma marca. A cidade não é uma empresa. A cidade é uma comunidade. Nós colocamos a questão social, que, nas cidades de hoje em dia, é também uma questão de luta pelo território. Trata-se de assumir o comando e defender locais que contribuem para que a vida na cidade valha a pena ser vivida, que não pertencem ao grupo-alvo da "cidade em crescimento". Reclamamos o nosso direito à cidade juntamente com todos os residentes de Hamburgo que se recusam a ser um factor de localização. (http://www.signandsight.com/features/1961.html)

5 Mas significará isto que a arte desempenhou nas cidades o seu papel de actividade crítica? Será que a resistência passou mesmo a fazer parte do espectáculo da cidade? 
Será que os artistas devem permanecer não-criativos, como argumenta a BAVO? Baseando-me numa análise da SpotCity, argumentarei que a arte pode resistir à tendência da privatização e da comercialização do espaço público e trazer questões políticas para a primeira linha do espaço público. No seu artigo "Making public interventions in today's massive cities", Saskia Sassen (2006) refere que as cidades são lugares para aplicar políticas concretas. Enquanto o Estado-nação é demasiado abstracto e dispõe de sistemas demasiado formais para as acções políticas, a cidade integra um grande número de diferentes acções políticas - manifestações, ocupações ilegais, intervenções -, a maioria das quais tem lugar e visibilidade nas ruas. E esta política ao nível da rua possibilita, afirma Sassen, que se formem novos temas políticos. Para além disso, muitas destas acções estão ligadas a questões globais. Porque a cidade também integra, de forma visível, uma mudança global nas ruas. A construção de teatros de ópera, como parte da imagem de marca da cidade, acontece à escala global tal como acontece com a polarização social das cidades. E isto é visível, mesmo que não seja objecto de debates políticos. Saskia Sassen afirma ainda que algumas entidades locais podem ser vistas como "micro-ambientes com dimensão global".

6 A SpotCity constituiu um desses micro-ambientes e o propósito deste artigo será analisar a forma como ela interveio nas políticas de lugar de Brunnsparken e transformou um local estigmatizado num momento espacial de utopia. Mas antes de começar esta análise devo apresentar a SpotCity e o objecto da minha pesquisa, fazendo posteriormente comentários introdutórios sobre o contexto da SpotCity, ou seja, sobre a revitalização e as condições pós-políticas da cidade de Gotemburgo.

\section{Ponto de partida}

7 A SpotCity realizou-se no centro da cidade de Gotemburgo durante três semanas, em Setembro de 2008, e foi iniciada por Tomas Ferm. O parque onde a SpotCity se localizou assemelha-se mais a um nó de trânsito e a um espaço de passagem do que a um verdadeiro parque. Neste espaço circulam por hora 250 autocarros e eléctricos em dez paragens diferentes de autocarro/

/eléctrico. O parque está localizado entre Nordstan, o maior centro comercial da Escandinávia, e um outro centro comercial mais exclusivo, o Arkaden. A Fredsgatan atravessa o Brunnsparken, onde mais de 100000 pessoas passam diariamente, sendo a rua mais populosa de toda a cidade de Gotemburgo. Apesar de o parque ser atravessado por muitas pessoas, ele não é concebido para esse efeito - é antes um espaço para o trânsito. As pessoas que utilizam regularmente esse espaço para deambular são pessoas que não têm para onde ir - os sem-abrigo e os jovens.

8 Uma vez que grande parte do restante centro da cidade tem vindo a ser concebido para os consumidores abastados, este espaço tem-se tornado um lugar de refúgio para os que não têm para onde ir e que por ali permanecem. Este facto deu má reputação ao parque. A visibilidade do parque também o tornou um local popular para pequenas manifestações. Tomas Ferm escolheu o Brunnsparken por diversas razões estratégicas. Queria estar numa área que fosse definida pelo consumo e pela ausência de instituições culturais. Também teria de ser um local onde diariamente passasse uma grande quantidade de gente. E, por último, Tomas Ferm pretendia ligar a sua arte aos desfavorecidos da cidade. A SpotCity foi um centro cultural temporário ao ar livre. Consistia em três edifícios que, em conjunto, criavam uma demarcação espacial do 
parque. Existia um contentor para a exibição de curtas-metragens - o contentor foi pintado pelo artista de rua Thomas Wiczac de forma a criar polémica. Existia um quiosque de arte com uma sala de convívio onde artistas ou movimentos sociais eram convidados a permancer e um palco para actuações. A SpotCity tinha também um poço projectado por Mandana Moghaddam, uma caixa móvel usada como mesa para conversar durante as refeições e por bancos para as pessoas se sentarem. Tomas Ferm foi o promotor do projecto mas também o seu curador. A SpotCity era uma obra de arte em si mesma mas incorporava também diversas obras de arte de diferentes artistas, e ainda actuações, declamação de poesia, música, conversas e debates.

9 Este artigo faz parte do projecto de investigação "Who gets the right to the city? Governance, resistance and conflict in public space" ("Quem tem direito à cidade? Governação, resistência e conflito no espaço público"), sobre como as parcerias públicoprivadas regem e regeneram os centros das cidades de Gotemburgo e de Estocolmo. 0 material empírico para o projecto baseia-se em entrevistas com intervenientes em parcerias público-privadas, em documentos oficiais das empresas, tais como operações, planos de acção, declarações, avaliações, protocolos de reuniões e em relatórios de segurança, assim como em anotações de reuniões e eventos.

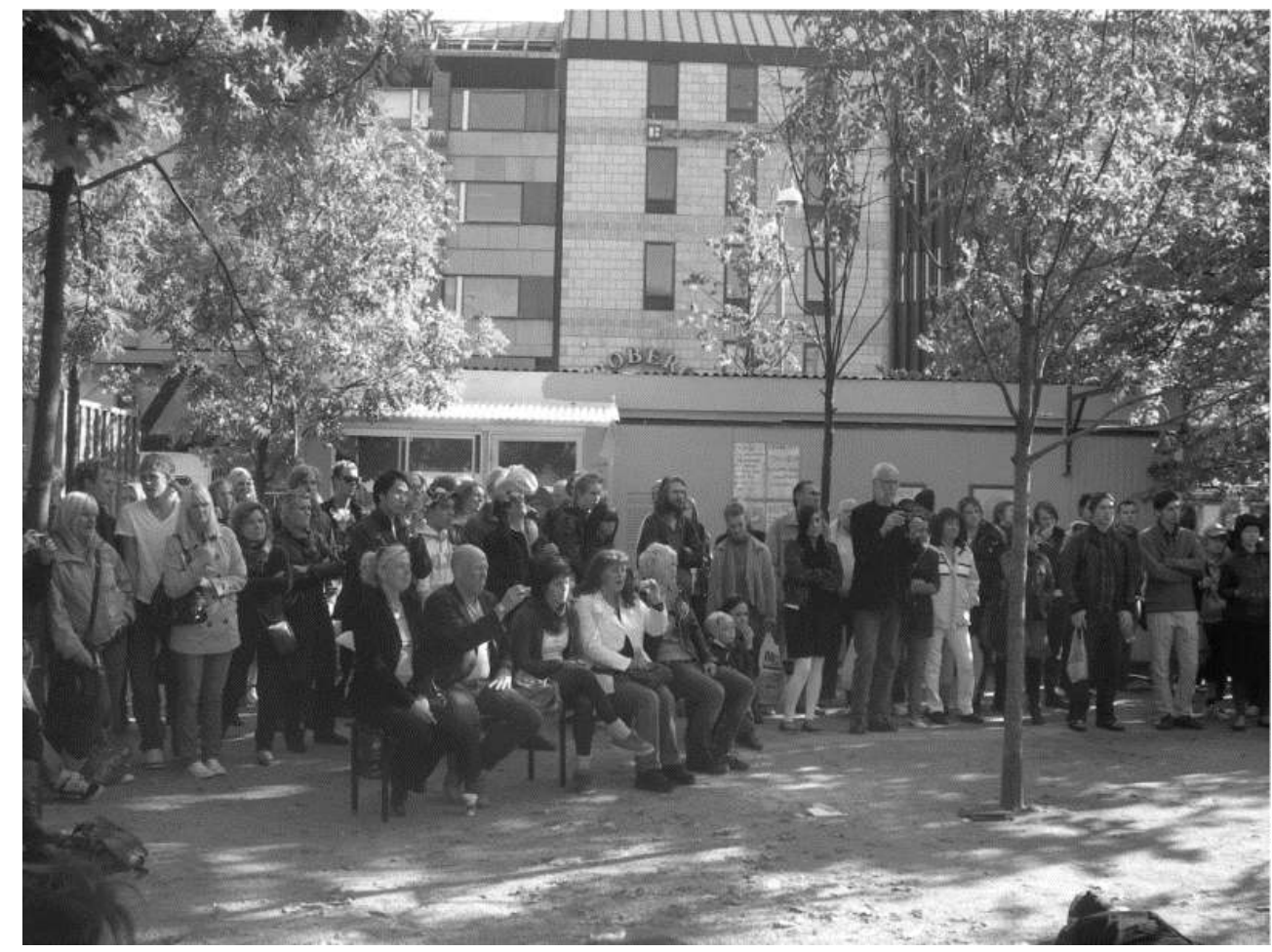

Pessoas a assistir a uma performance

Neste projecto de investigação, utilizei o caso da SpotCity por um lado como uma lente, para analisar a forma como a arte pode criar espaço público no centro da cidade e, por outro, como um contrapeso relativamente ao trabalho das parcerias públicas e privadas quanto à separação e intervenção no espaço público. Assim, neste artigo não farei a crítica da SpotCity no seu todo, uma vez que, durante essas três semanas, muitas actividades tiveram lugar. Em vez disso, identificarei algumas das actividades e analisarei, em especial, a forma como a SpotCity accionou o espaço público em diferentes escalas que designo por espaço público comum, o microespaço "glocal" e a mobilização do público. 

SpotCity. Também visitei a SpotCity quase diariamente, com algumas excepções - só por algumas horas ou durante o dia inteiro. Durante este período, tomei extensas notas. Sentei-me na audiência durante as actuações mas também após as actuações, quando a audiência culturalmente interessada já tinha saído e quando as pessoas que não tinham para onde ir usavam a área para estarem umas com as outras.

Também falei com gente que ali se encontrava e que tinha assistido às actuações. Além disso, fiz entrevistas às organizações que tinham sido convidadas para a SpotCity, como a Iwanthousing.now, e também a dois dos artistas convidados, Mandana Moghaddam e Elin Wikström.

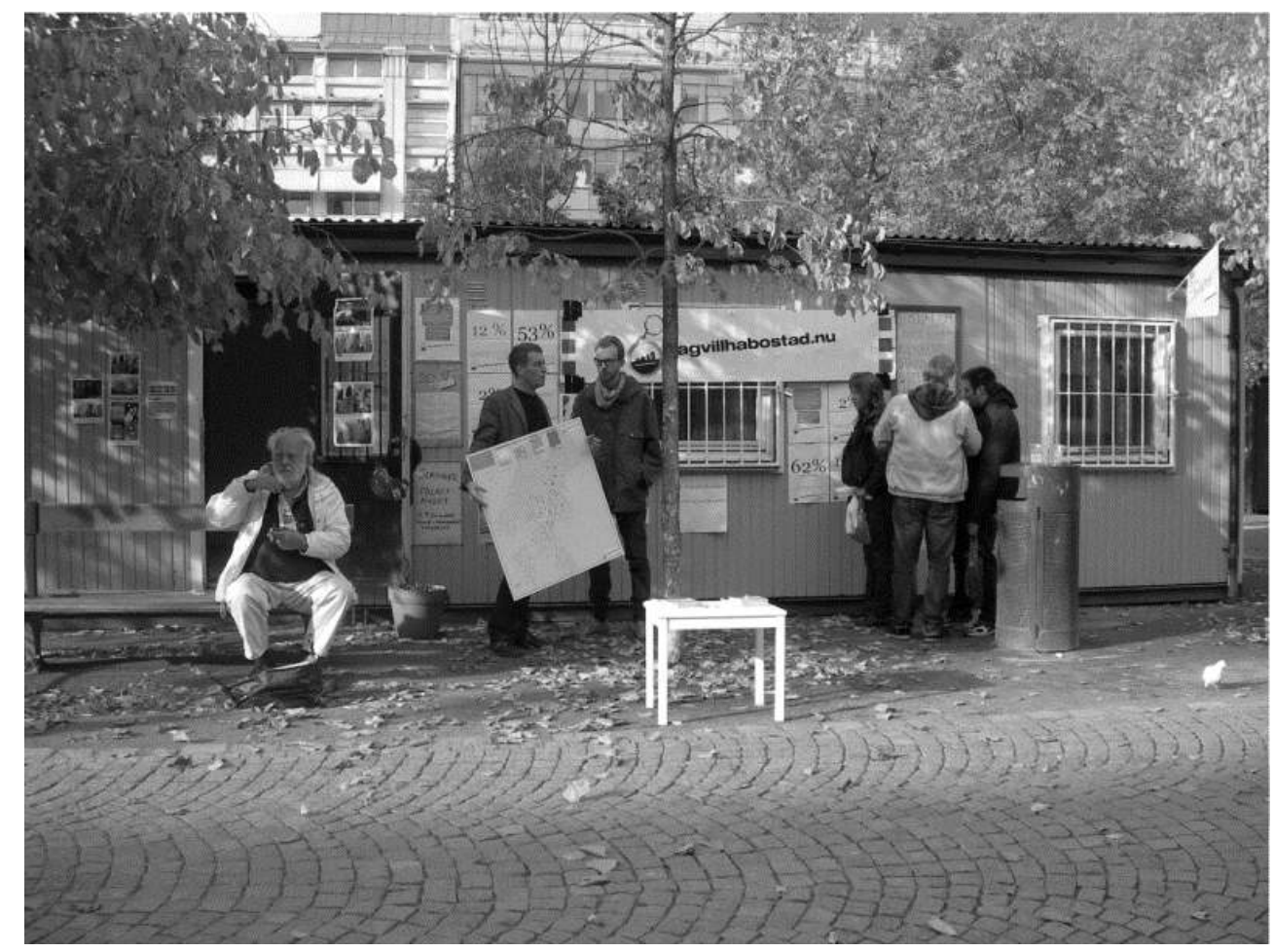

Iwanthousing.now na sala de convívio

\section{Gotemburgo - perfil da uma cidade pós-política}

A pólis está morta. Viva a cidade criativa! Enquanto a cidade está viva e próspera - pelo menos em alguns dos seus espaços - a pólis, concebida a partir do sentido grego idealizado como o lugar para o encontro público político e para a negociação democrática, o espaço (muitas vezes radical) para a divergência e desacordo e o local onde a subjectivação política tem literalmente lugar, parece estar moribunda (Swyngedouw, 2007: 59).

14 No seu artigo "The Post-Political City" (“A Cidade Pós-Política”), Erik Swyngedouw argumenta que essas cidades se tornaram "a principal arena através da qual o consenso pós-político é construído" (2007: 66). Swyngedouw e outros, como David Harvey e Neil Smith, referiram que hoje em dia a reestruturação do espaço urbano, com frentes marítimas exclusivas, edifícios de referência, hotéis de luxo, campanhas institucionais de marcas, etc., faz parte da governação global neoliberal mais alargada que privilegia o 
crescimento e cria uma distribuição desigual (e injusta) desse crescimento dentro das cidades. Isto significa que o crescimento económico pode ser florescente numa parte da cidade enquanto outras partes da cidade estão a ser drenadas de recursos. Este desenvolvimento torna-se pós-político quando, tal como Thatcher uma vez referiu, "não existe alternativa". Portanto, a "pós-política" tem tudo a ver com o ajustamento da cidade às estruturas económicas globais - tornando-a atractiva para os investidores, para competições globais, tais como os Jogos Olímpicos ou o Campeonato do Mundo de Futebol, e para o turismo. Em Gotemburgo este desenvolvimento já data da década de 80 mas cresceu a um ritmo bastante lento até 2000 , altura em que o desenvolvimento se acelerou.

15 Em 2006, os políticos de todos os partidos democráticos de Gotemburgo decidiram que as tradicionais tendas eleitorais, o verdadeiro símbolo da democracia na Suécia, deveriam ser banidas durante algumas semanas de Agosto das campanhas eleitorais a nível nacional. A razão para esta decisão radical prendeu-se com a realização, na cidade, dos Campeonatos Europeus de Atletismo em Pista e de Corta-Mato, pelo que os políticos viram uma grande oportunidade para colocarem a cidade no mercado e para apresentarem cenas pitorescas de Gotemburgo durante a competição. Os políticos concordaram que as tendas eleitorais podiam causar uma impressão confusa na TV e perturbar a imagem da cidade. Os políticos e a democracia ficaram literalmente subordinados ao marketing da cidade.

16 A partir da década de 80, Gotemburgo passou de uma cidade portuária e industrial a uma cidade de eventos, com uma frente marítima exclusiva e com um centro cuidadosamente requalificado de forma a criar uma imagem de marca. As parcerias públicas e privadas trabalham lado a lado no sentido de criarem a atmosfera certa para a cidade, imagem essa que atraía os investidores e a classe criativa. Em poucos anos muito aconteceu - ruas renovadas, novas design boutiques e cafés de estilo italiano abriram, substituindo os antigos cafés das classes trabalhadoras. A arte e o design passam agora a ter um papel central nesta reconstrução - algumas ruas, como a Magasinsgatan ou a Andra Långgatan, estão a ser requalificadas como ruas destinadas à camada de jovens criativos. Com vista à criação destes locais, a cidade utiliza activamente a gentrificação como uma estratégia fulcral para a renovação urbana e legitima-a fazendo referências ao seus "efeitos multiplicadores em cascata".

Nestes processos, a cultura tem um papel central na criação de uma atmosfera impondo um enquadramento sensual ou sensescape no tecido urbano. Por um lado, Gotemburgo olha para esta sensescape como uma estratégia de saneamento que remodela e redefine os espaços públicos, que excluem as pessoas indesejadas tais como os sem-abrigo, ou os sinais visuais indesejados, como os graffiti. Por outro lado, existem estratégias de "imagineering" (imaginação técnica) que visualizam o centro da cidade como um lounge, com ambiente e códigos de classe média com o propósito de disfarçar a dura realidade da vida de rua dos excluídos (Thörn, 2011). Em conjunto, estas estratégias criam um ambiente no espaço público de uma certa coolness e de valores de classe média. Cria igualmente uma política de lugar em que alguns locais são imbuídos de propriedades carismáticas enquanto outros se tornam estigmatizados e são vistos como deslocados (Franzén, 2005). Quando o The New York Times chamou a atenção para Gotemburgo como a próxima cidade sueca de referência, enfatizou o contributo dos artistas para a coolness da cidade:

A pequena Gotemburgo - a sua população anda à volta de meio milhão - é endiabrada, resistente, criativa e com laivos de alguma impulsividade obscura e 
insegurança. No passado, os suecos teriam aqui tirado os seus cursos superiores (é a maior cidade universitária do país) e depois migrado. Mas cada vez mais os músicos, artistas, designers e os pequenos empreendedores - a cultura mais jovem que dá à cidade a sua vitalidade libertina e, eventualmente, a sua vitalidade económica estão a ficar ou a regressar, a última vaga de suecos e não suecos a colonizar Gotemburgo para seu próprio benefício. (The New York Times, 23 de Setembro de 2007)

Em Janeiro de 2012, o novo hotel de luxo, o Clarion Post, será inaugurado. O hotel está situado na antiga Estação de Correios no centro da cidade e joga deliberadamente com o discurso da classe criativa. No seu sítio na internet, apresentam-se ao mercado como fazendo parte da "Nova Gotemburgo":

O Hotel Clarion Post é um tipo de hotel de negócios completamente diferente situado no coração da cidade. $\mathrm{O}$ hotel constituirá um ponto de encontro moderno e central para todos os visitantes da cidade. Para além disso, o hotel servirá de sala de estar para todos os residentes de Gotemburgo que se sentem mais confortáveis inseridos na nova imagem da cidade do que nos seus ambientes históricos do porto e da indústria pesada. (http://www.clarionpost.com/the-new-gothenburg, visualizado a 17-10-11)

19 Parte do sucesso desta transformação pode ser explicado pelo chamado Göteborgsandan (o espírito de Gotemburgo). Nesta cultura política de consensos que desde há muito vem dominando a cidade, os conflitos de interesses são comedidos e, muitas vezes, tornam-se invisíveis (ver também Quilley, 1999, sobre Manchester). Este legado histórico (Falkemark, 2010) foi restabelecido durante a liderança do comissário municipal, Göran Johansson, desde há muito o presidente do Partido Social Democrata em Gotemburgo. Com antecedentes em política sindical, conseguiu ganhar legitimidade pelas suas políticas para a classe trabalhadora e também para a elite empresarial, com o objectivo de desenvolver um clima favorável propício aos negócios, de modo a adequar a política da cidade à globalização. Nos últimos dez anos, isto resultou num desenvolvimento da cidade relativamente rápido e na reputação de que "as coisas acontecem". Efectivamente, esta cultura política está até inscrita na imagem de marca de Gotemburgo. Por exemplo, no sítio da internet dirigido aos investidores internacionais pode ler-se:

Gotemburgo é uma grande cidade, com uma importante comunidade empresarial, universidades, cultura, desportos e eventos. No entanto, dispõe de uma atmosfera de pequena cidade, onde existe uma cooperação ímpar e uma visão de conjunto por parte dos políticos, da comunidade empresarial e das universidades. Isto é conhecido como o "O Espírito de Gotemburgo". o processo de tomada de decisão é fácil e pode-se chegar a acordo sem dificuldades de maior - o que é um aspecto de grande importância quando se trata de organizar eventos de larga escala. (http:// www.goteborg.com/en/Header/Meetings/About-Gothenburg/A-Meetings-andEvents-City/)

20 Mesmo sendo Gotemburgo considerada um paraíso seguro e amigável, essa imagem constitui somente um dos lados da questão. A cidade tem registado recentemente cada vez mais problemas ligados à segregação, ao aumento da pobreza e ao aumento do número dos sem-abrigo. Um relatório publicado recentemente indica que Gotemburgo se tornou uma cidade cada vez mais polarizada a nível social, com um centro abastado, com subúrbios ricos a sul e subúrbios pobres a norte (Andersson et al., 2009). Mas estes problemas raramente são discutidos a nível político - em vez disso, o planeamento urbano em Gotemburgo é-nos apresentado como sendo a construção da "boa cidade". 


\section{A construção do espaço público}

\section{A criação da publicidade vulgar}

21 Uma das pedras angulares da SpotCity foi a tentativa de criar um espaço público num local utilizado para o trânsito. Foram construídos diversos "edifícios" de forma a criar a sensação de uma zona separada onde se pudesse andar, conversar com pessoas, ver cinema ou assistir a espectáculos. A SpotCity estava aberta ao público entre as $10 \mathrm{da}$ manhã e as 7 da tarde e oferecia um programa diário. Mas o mais importante era talvez o facto de que o próprio artista passava algum tempo no local e passava a conhecer as pessoas que habitualmente deambulavam pela zona. Tomas Ferm argumenta que, assim, a arte terá de funcionar em função das condições impostas pela rua. E explicou:

Este local pertence à rua, com as suas regras. Se está à espera de estar num museu em que tudo está em perfeita ordem e se espera que isso faça parte do espaço da arte, então precisa de pensar melhor.

Visto que o Brunnsparken é um local por onde andam pessoas sem-abrigo, isso também significou que a SpotCity de certo modo se intrometeu na sua zona e alterou radicalmente o seu espaço. Portanto, a confiança entre o artista e os habitantes da zona teve de ser estabelecida. Antes da abertura da SpotCity quando o palco e o quisoque de arte estavam em fase de construção e pintura, Tomas Ferm teve a oportunidade de falar para e com as pessoas sobre a SpotCity. Durante as três semanas em que decorreu a SpotCity, os sem-abrigo e os alcoólicos foram a audiência mais regular e foram eles que assistiram à maior parte das actuações de palco, tendo dado a sua opinião sobre o que viram. Os bancos aí colocados foram utilizados não só para assistirem ao que se passava no palco mas também para se sentarem e descansar, comerem "comida de plástico", para entabularem curtas conversas com quem passava e para estarem com os amigos.

Visto a SpotCity ter durado três semanas, os visitantes regulares passaram a conhecerse uns aos outros muito bem, do que resultou um ambiente amistoso. Visto que eu mesma fui um visitante regular e não fiz muito mais do que deambular por ali, tive oportunidade de conversar com muita gente. Um homem, que normalmente dormia em abrigos de acolhimento, tornou-se um visitante regular desde o primeiro dia. Conversávamos alguns momentos todas as manhãs e ele tinha sempre muitos comentários a fazer sobre as actuações. Notei também que muitas pessoas contactavam Tomas Ferm frequentemente, fazendo perguntas, discutindo assuntos ou simplesmente pedindo ajuda - perguntando direcções ou pedindo dinheiro. Fiz várias entrevistas no local com o Tomas, e éramos constantemente interrompidos com questões, observações e histórias pessoais. Nesta atmosfera, tornou-se fácil falar sobre o objectivo da SpotCity - em que tipo de cidade se transformou Gotemburgo e o que podia vir a ser. 


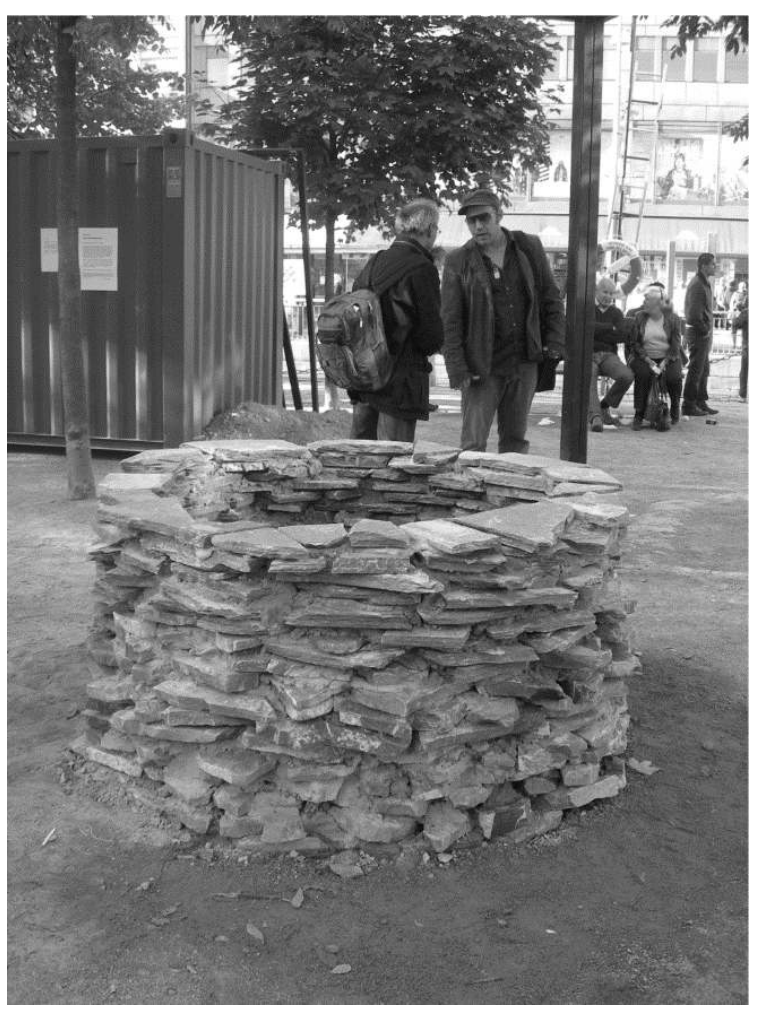

O Poço

almoços. Diariamente, ao meio-dia, homens de negócios de fato, em pequenos grupos, atravessavam a SpotCity para ir almoçar. Isto significou que tiveram de alterar o seu trajecto normal, tiveram de abrandar o seu andamento e ziguezaguear entre as pessoas que por ali andavam. $O$ facto de eles nunca terem parado ou mesmo olhado para o que os rodeava fez com que o seu percurso diário através da zona fosse bastante notado. Na SpotCity eles tornaram-se (por escolha) os intrusos - pessoas que não pertenciam e não queriam pertencer a essa zona. Em contraste com todas as pessoas que aí se reuniam, eles insistiram em utilizar esse espaço como zona de passagem. Após algum tempo, os seus percursos através da zona quase se tornaram simbólicos e as pessoas comentavam a sua ignorância sobre o que se estava a passar na SpotCity. almoço um funcionário público, um político ou quaisquer outras pessoas que tivessem muita influência no planeamento urbano. Alguns exemplos de pessoas convidadas foram: protagonistas do evento, tais como o director da companhia Inner City Gothenburg, que é uma empresa gerida por proprietários de imóveis e de empresas de negócios com o objectivo de fazer melhoramentos no centro da cidade, o principal responsável do Departamento de Planeamento da Cidade e o principal responsável para os assuntos culturais em Gotemburgo. A conversa teve lugar à volta de uma mesa móvel que estava colocada ao longo da rua principal por onde passa um grande número de pessoas. Não havia nem palco nem microfone, porque a intenção era manter uma conversa informal em que as pessoas pudessem intervir quando quisessem. Também devia servir para minimizar a distância entre as "pessoas comuns" e a elite do poder.

A SpotCity dispunha também de uma sala de convívio onde os movimentos sociais eram convidados a ficar e a falar sobre os problemas relacionados com as pessoas. Um desses 
grupos era o Iwanthousing.now, uma organização gerida por jovens que se mobilizam em torno de questões relacionadas com a habitação. Em muitas cidades suecas, em particular em Gotemburgo, existe falta de habitação a preços acessíveis, facto que é especialmente problemático para os jovens. Quando visitaram a SpotCity utilizaram um grande mapa de Gotemburgo e perguntaram aos visitantes onde queriam que fossem construídas mais habitações e de que tipo. Este mapa foi objecto de muita discussão, não só acerca da habitação mas também acerca do planeamento urbano. No fim da visita da Iwanthousing.now à SpotCity, fizeram um desvio até ao departamento governamental para entregar o mapa aos políticos.

Vários artistas foram convidados a utilizar o espaço da SpotCity. Um desses artistas foi Åsa Sonjassdotter, que elaborou o trabalho: "Se você não o cultivar não o saberá. Se você não o souber não o cultivará - um arquivo sobre o poder visível”. O seu trabalho trata das Directivas da UE e de como uma coisa comum, como plantar batatas pelos métodos tradicionais e vendê-las, pode tornar-se um acto ilegal na UE, visto que estes não estão registadas nem se enquadram nas regras da normalização da batata da UE (para mais informações consultar http://www.potatoperspective.org/). 0 seu projecto foi cultivar algumas destas batatas numa pequena área do centro da cidade, a 200 metros da SpotCity, e servi-las depois às pessoas. Isto provocou uma discussão sobre as Directivas da UE mas teve também como resultado peculiar o facto de a típica audiência de arte ter de estar na fila juntamente com pessoas que só lá estavam, não pela arte, mas sim para arranjar alguma comida.

\section{Microespaço glocal}

Eu argumentaria que, mesmo que a criação de um espaço público vulgar tenha sido a pedra angular da SpotCity, um aspecto importante foi o de trazer questões globais para o espaço local e para o centro da cidade - tanto literal como simbolicamente. De certo modo, o local de Brunnsparken estava disponível para estruturas globais ao relacionar a história de Gotemburgo com lugares e histórias de outros locais. 


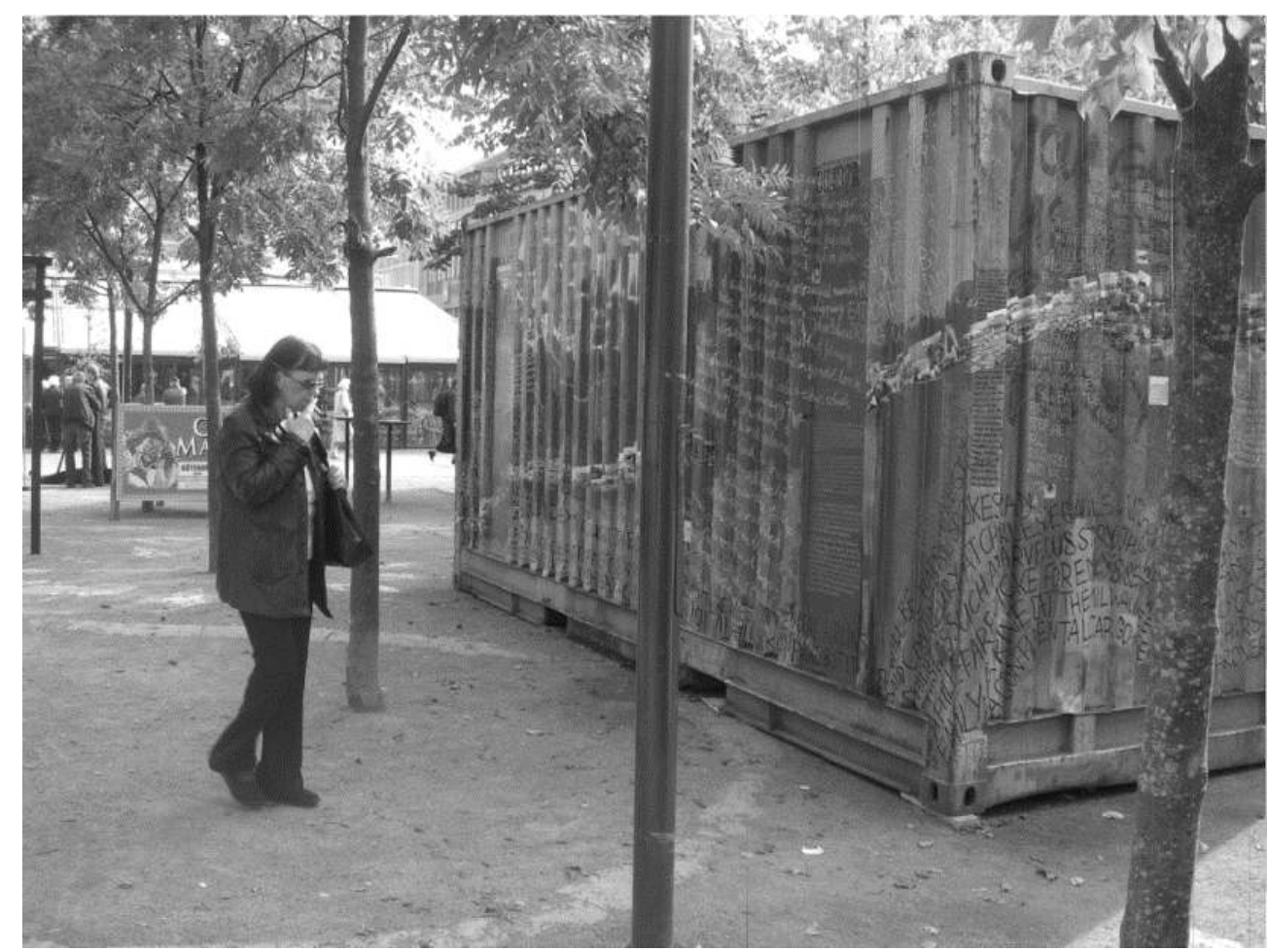

O contentor

Por exemplo, foi utilizado um contentor para a exibição de filmes. Numa cidade portuária como a de Gotemburgo, o valor simbólico de um contentor é significativo. Simboliza a época dos estaleiros navais ou, quando colocado no centro da cidade, o final dessa época. Em Gotemburgo, a paisagem urbana alterou-se dramaticamente nos últimos 20 anos e a maior parte do antigo porto foi transformada num cluster de empresas de tecnologia de informação e em habitações de luxo. Mas o contentor também simboliza a mudança para o exterior e histórias de outras partes do mundo. 0 artista Thomas Wiczac foi incumbido de pintar o contentor. Escolheu o tema globalização e movimento. Nas paredes do contentor contou histórias de gatos que tinham sido fechados em contentores e transportados para todas as partes do mundo. No contentor pintou mapas mostrando o seu percurso por todo o mundo e cada gato tinha uma fotografia individual com a sua história pessoal. As simpáticas histórias dos gatos sendo resgatados revelaram-se uma feliz coincidência relativamente ao conteúdo de alguns filmes que foram exibidos no contentor. Os temas dos filmes foram: migrações, refugiados e contrabandistas. Três filmes diferentes retratavam as duras vidas dos imigrantes. O filme The Short Cut de Rafael Deugenio retratava o destino de imigrantes que eram transportados ilegalmente dentro de um contentor quando o motorista do camião teve um ataque de coração e morreu, tendo eles ficado encerrados no contentor. Ver esse filme dentro de um contentor provocou uma sensação claustrofóbica. Na altura do projecto da SpotCity, a discussão, em Gotemburgo, sobre o transporte ilegal de refugiados era muito tensa. Alguns meses antes da SpotCity, o comissário municipal, Göran Johansson, tinha proposto, através dos órgãos de informação nacionais, uma alteração da lei que permitiria deportar imediatamente todos aqueles que entrassem ilegalmente na Suécia. Este depoimento provocou um grande debate, tendo ele recuado mais tarde, declarando que só tinha sido provocador para chamar a atenção para este grave problema. Mas não tinha sido essa a primeira 
vez que Göran Johansson fizera declarações provocatórias sobre migrações. Tinha também sido crítico relativamente ao direito legal que assiste a quem pede asilo de viver onde quiser, sugerindo uma lei que obrigasse as pessoas a viver em cidades mais pequenas com mais para oferecer do que a cidade de Gotemburgo (Holgersson, 2011). Isto desencadeou, em Gotemburgo, um debate sobre migrações, racismo e segregação. A SpotCity trouxe este debate para o centro, concedendo espaço à organização. Ninguém está ilegal na sala de convívio. Durante três dias permaneceram no exterior da sala de convívio dando informação sobre migrações e mantiveram-se disponíveis para responder a perguntas e promover discussões.

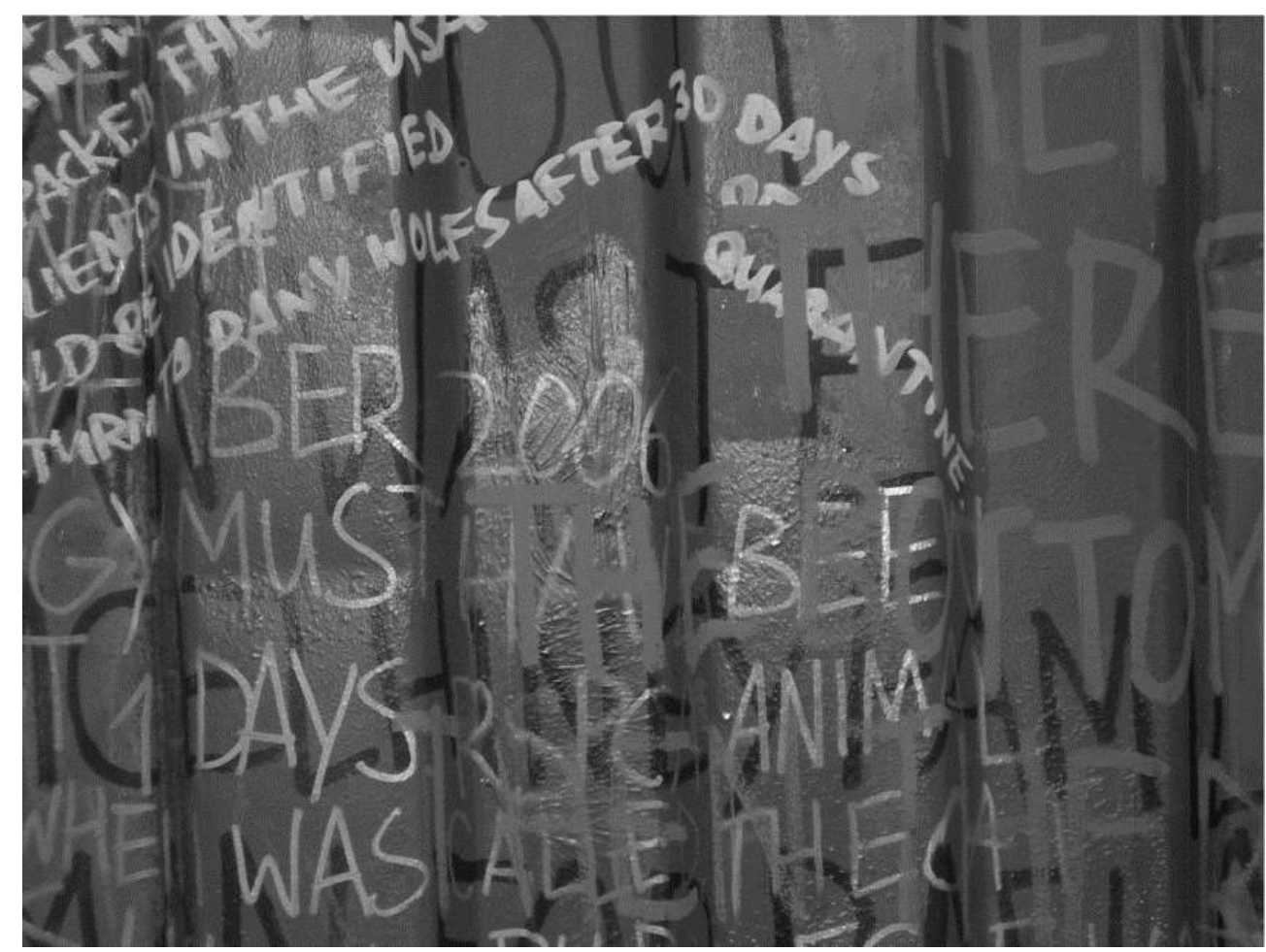

UM gRANDE PLANO DO CONTENTOR

Mas os problemas globais foram também trazidos para a primeira linha através da obra de arte Brunnen ("O Poço"), de Mandana Moghaddam, uma refugiada iraniana. A ideia de O Poço nasceu quando ela tinha acabado de chegar à Suécia. Ao passar muito tempo numa cabina telefónica tentando contactar com a família no Irão, ela interessou-se por questões relacionadas com comunicação e exílio. Teve assim a ideia de criar a possibilidade de estabelecer uma ligação entre pessoas que estivessem em diferentes locais. A ideia foi criar poços físicos em diferentes cidades e utilizar as modernas telecomunicações para ligar os poços uns aos outros. Dessa forma, as pessoas podiam comunicar através do poço e as pessoas noutra cidade podiam responder. Isto criaria uma sensação de familiaridade entre pessoas em locais distantes. O símbolo do poço foi escolhido visto ter um grande valor icónico em muitas culturas - tanto em contos de fadas como nas religiões. Tal como ela declara, "É um símbolo dos sonhos". E o sonho da própria artista foi o de criar uma sensação de pertença entre cidades distantes. No Brunnsparken, que na verdade se traduz por "O Parque dos Poços", a artista quis abrir uma linha entre Gotemburgo e Teerão. Pediu uma licença em ambas as cidades e dois poços foram construídos. À última hora, a licença de Teerão foi cancelada. Segundo Mandana Moghaddam, as razões deveram-se ao facto de as autoridades no Irão 
temerem que ele pudesse ser usado pelos iranianos em Gotemburgo para difundir mensagens políticas para o Irão. Isso também podia ser entendido como paródia contra o poço sagrado do imã. Mesmo tendo sido cancelada a licença de Teerão, o poço de Gotemburgo foi inaugurado e utilizado para fomentar a discussão e a consciencialização para as condições políticas no Irão. Até hoje, $O$ Poço ainda se mantém e em 2009 foi de novo inaugurado ligando-se aos poços de Seul, na Coreia do Sul.

\section{Mobilizando os públicos}

31 No centro das estratégias de renovação está a regulação e o controlo sobre o espaço público. A presença visível dos sem-abrigo, da criminalidade de rua e de graffiti não só é vista como uma ameaça potencial à credibilidade da imagem da cidade - comercializada pelos que estão no poder - mas também como símbolo de decadência e insegurança. A consequência é o surgimento de diversas iniciativas públicas e privadas para "limpar" os centros da cidade. Há, hoje em dia, na Suécia, vários exemplos desta tendência que tem vindo a aumentar, incluindo, entre outras, a proibição, proposta há já alguns anos mas não promulgada, de pedir esmola em Estocolmo; experiências de tolerância zero mais apertadas por parte da polícia e a criação de diversas parcerias público-privadas reforçam os interesses dos proprietários de lojas e de imóveis numa cidade comercialmente atractiva. Nos finais de 2004, o governo sueco decidiu aumentar as penalizações para aqueles que pintassem graffiti. 0 governo decretou ainda que a polícia tinha o direito de fazer "revistas corporais, preventivas", mesmo sem ter suspeitas de algum delito ter sido cometido. Uma característica comum entre as várias propostas foi o facto de terem como ponto de partida a prevenção do crime. O crime ou simplesmente as ameaças à ordem e à segurança nos espaços públicos devem ser prevenidos antes de cometidos. Roy Coleman tem referido que o actual controlo nas cidades está "estrategicamente interligado e articulado com os espectáculos visuais que promovem formas de ver o espaço urbano como um espaço positivo, «centrado nas pessoas» e festivo" (Coleman, 2005: 132). Em Gotemburgo, o discurso político sobre os graffiti sofreu uma dramática alteração em poucos anos - foi mesmo visto como uma prática artística merecedora de legislação aplicável de tolerância zero. Uma regulamentação contra os graffiti foi produzida por uma parceria conjunta entre as autoridades locais, a polícia e os proprietários de imóveis, dizendo estes que a cidade deve ser muito restritiva quanto às autorizações legais para elaboração dos graffiti. $\mathrm{E}$ escrevem:

Existe um enorme risco de que o espaço livre para decoração seja contraproducente e induza a pinturas ilegais nas áreas circundantes. Em Gotemburgo não existe qualquer espaço em que sejam permitidos os graffiti ou qualquer outra decoração se o mesmo não for acompanhado pelas necessárias disposições regulamentares e conjuntas da sociedade e das autoridades, tais como escolas, serviços sociais e polícia. ("Política para uma cidade agradável", 2007-09-17)

Seguidamente, em Setembro de 2008, a companhia do Teatro Nacional (Riksteatern) viria a Gotemburgo com o seu espectáculo Quatro Dias de Hip Hop. 0 tema do espectáculo eram os quatro elementos do hip hop - dj, graffiti, dança e rap. Consistia em actuações de dança, de música, workshops, debates, etc. Em Gotemburgo, a companhia convidou um conhecido pintor de graffiti para pintar uma tela em frente à audiência. Esta actuação teria lugar numa tenda no exterior do teatro. No entanto, as autoridades decidiram negar a autorização para a tenda caso alguém pintasse quaisquer graffiti (mesmo sendo 
executados numa tela - que não era nem propriedade privada nem pública). Com esta decisão, o recentemente nomeado Responsável para os Assuntos Culturais apanhou de surpresa os organizadores do Teatro Nacional. O facto de o Responsável para os Assuntos Culturais ter tomado esta decisão oficial transformou esta questão de ordem pública numa questão sobre valores culturais.

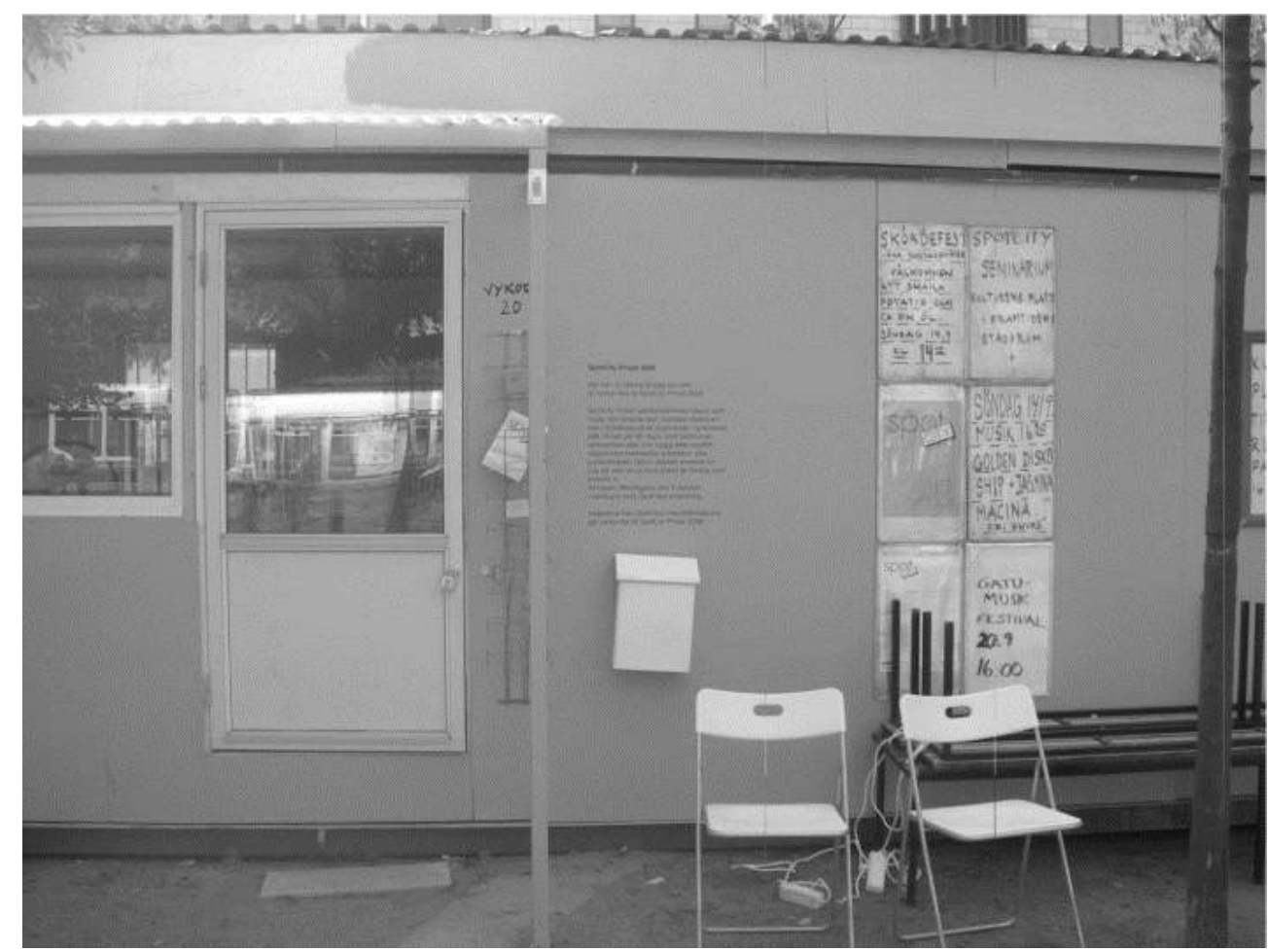

O quiosque de arte onde as pessoas podiam informar-se sobre a SpotCity e falar com Tomas Ferm, o artista

Uma vez que isto sucedeu durante a SpotCity, que tinha por objectivo provocar a discussão sobre o papel da arte e da cultura na cidade, Tomas Ferm foi rápido quer a reagir contra a decisão, quer a convidar o Responsável para os Assuntos Culturais para uma discussão na talkbox. Também marcou uma reunião e colocou posters nos edifícios da SpotCity dizendo: "Censura estética em Gotemburgo - reunião hoje às $18 \mathrm{~h}$ ". 0 Responsável para os Assuntos Culturais aceitou o convite e apareceu na SpotCity. Esta conversa foi a que teve maior participação em todo o período que durou o evento. Muitas pessoas, sobretudo jovens, juntaram-se para terem a oportunidade de falar com o Responsável para os Assuntos Culturais. Apesar de ter sido uma acesa discussão, o facto de ter tido lugar na rua, no espaço público, onde os jovens podiam demonstrar as suas preocupações e evidenciar os seus diferentes pontos de vista, foi realmente muito importante. À noite as pessoas juntaram-se na SpotCity para discutirem o papel da arte na cidade e o que podia ser feito para se criar mais espaço para a arte em Gotemburgo.

\section{Conclusão}

Já tinha afirmado que a sobrevivência e alargamento do espaço público é uma questão política. O que pretendo explicar é que se trata de uma questão que está no cerne da democracia. O que é que está em causa nos espaços públicos das cidades de hoje? 
Porque é que se torna importante defender e alargar a noção de espaço público aberto? E qual é o papel da arte nestes processos? (Lefort, 1988.)

Actualmente, em muitos centros de cidade, os espaços públicos são vistos, cada vez mais frequentemente, como fazendo parte das estratégias de reabilitação que se focalizam no desenvolvimento da imagem positiva do centro da cidade como sendo "atractivo e seguro". E Gotemburgo, com a sua frente marítima recentemente renovada, a reabilitação do centro da cidade e a regeneração baseada no design, atrai consumidores da classe média para viverem, passearem e consumirem as ruas do centro da cidade, ao mesmo tempo que são criados espaços fora do centro da cidade para os sem-abrigo.

Isto não se passa só em Gotemburgo, acontecendo também em muitas outras cidades. Os artistas são muitas vezes convidados a participar, especialmente depois da influência de Richard Florida e da sua declaração sobre a importância da classe criativa. Mas alguns artistas indignam-se contra estes desenvolvimentos e, quando isto acontece, por vezes identificam claramente estes processos como limitadores do nosso entendimento sobre o que é o espaço público. Em Hamburgo, os artistas referiram que a arte está reduzida a um factor de renovação e não é um valor em si mesma. Mas a arte também pode ter um papel central na resistência contra estas estratégias - defendendo o direito ao espaço - para a arte e também para todos os habitantes da cidade.

37 A SpotCity é um exemplo de uma intervenção artística que, durante três semanas, usou a cultura para abrir espaço público tornando-o mais acessível, usando-a também para organizar encontros e discussões entre as pessoas. Localizada no Brunnsparken, a SpotCity implantou-se num espaço que se baseia no movimento - entre autocarros, ou de passagem para/de centros comerciais. Poucas são as pessoas que realmente aí permanecem, à excepção das que não têm onde ficar. A SpotCity conseguiu que o movimento abrandasse e transformou a área num local de encontro sem quaisquer apelos ao consumo. $\mathrm{O}$ risco de um tal projecto de arte é o de afastar os habitantes da zona e promovê-lo a espaço para eventos. A SpotCity não fez isso - muito devido ao trabalho do artista Tomas Ferm. 0 seu intuito foi sobretudo fazer dele um projecto dirigido às pessoas que já lá estavam e posteriormente convidar quem passasse nessa zona. Desta forma a arte e a cultura podem ter um papel na reabertura e na ampliação das utilizações e noções de espaço público. Tal como Don Mitchell disse, o espaço público não é uma coisa que exista, mas que precisa de ser criada vezes sem conta. E escreveu:

Expandir o direito à cidade requer um foco claro nas possibilidades utópicas e os perigos de procurar incessantemente reabrir e, portanto, reformar o espaço público à imagem de uma ordem urbana mais justa. (Mitchell, 2003: 236)

A SpotCity utilizou a cultura para transformar um local estigmatizado num lugar de utopia. Por breves momentos na história, uma audiência muito heterogénea encontrouse, conversou e trocou experiências culturais. Isso não significou que as diferenças entre as pessoas tenham desaparecido - na fila, à espera de que servissem as batatas, as desigualdades entre as pessoas eram bastante evidentes. Em vez de ignorar estas diferenças ou as "esteticizar", a SpotCity transportou-as para a frente do Brunnsparken - permitiu que as pessoas assumissem o espaço e estivessem presentes. Quando os espaços públicos nos centros de cidades se tornam mais homogéneos, a função democrática do espaço público como espaço onde a sociedade se torna visível enfraquece. 
Hoje em dia, a arte desempenha um papel duplo neste desenvolvimento. Por um lado existe arte que contribui para a imagem de marca da cidade, para a publicidade positiva que anula as desigualdades e que representa o espaço público como sendo harmonioso e seguro. Por outro lado, a arte pode, tal como aconteceu na SpotCity, contribuir para a construção de um espaço público mais alargado - como um espaço de política, onde as diferenças e os conflitos ganham visibilidade pela criação de uma publicidade crítica.

\section{BIBLIOGRAFIA}

ANDERSSON, R. et. al. (2009), Fattiga och Rika - Segregerad Stad [Poor and Rich - segregated City] Stadskansliet och Social Resursförvaltning, Göteborgs Stad.

COLEMAN, R. (2005), "Surveillance in the City: Primary Definition and Urban Spatial Order", Crime, Media, Culture, 1, pp. 131-148.

DEUTSCHE, R. (1998), Evictions. Art and Spatial Politics, Cambridge, MIT Press.

FALKEMARK, G. (2010), “A study of the «Gothenburg Spirit»” in Holgersson, H., C. Thörn, H. Thörn e M. Wahlström (eds.), (Re)Searching Gothenburg, Gotemburgo, Glänta.

FRANZÉN, M. (2005), “Mellan stigma och karisma. Stureplan, Sergels torg och platsens politik", Fronesis, 18.

HOLGERSSON, H. (2011), Icke-medborgarskapets urbana geografi, Gotemburgo, Glänta Förlag.

LEFORT, C. (1988), Democracy and Political Theory, Cambridge, Polity Press.

METCALF, S. (2007), “Sweden Unzipped”, The New York Times, 23 de Setembro de 2007.

MITCHELL, D. (2003), The Right to the City. Social justice and the fight for public space, Nova Iorque, The Guildford Press.

SASSEN, S. (2006), "Making Public Interventions in Today's Massive Cities", HYPERLINK "http:// www.columbia.edu/ sjs2/PDFs/sassen_publicintervensions_2006.pdf” Static, Issue 04, London Consortium.

SWYNGEDOUW, E. (2007), "The Post-Political City", BAVO (ed.), Urban Politics Now. Re-Imagining Democracy in the Neo-Liberal City, Roterdão, NAI Publisher.

THÖRN, C. (2011), "Soft policies of exclusion - entrepreneurial strategies of ambience and control of public space in Gothenburg, Sweden”, Urban Geography, 32(7), pp. 989-1008.

QUILLEY, S. (1999), “Entrepreneurial Manchester: The Genesis of Elite Consensus”, Antipode, 31, pp. 185-211.

\section{ANEXOS}

Endereços electrónicos: 
Clarion Hotel (s.d), The New Gothenburg. http://www.clarionpost.com/the-newgothenburg

Spot City (2008). www.spotcity.se

Signandsight (2009), Not in our name! Jamming the gentrification machine: a manifesto. http://www.signandsight.com/features/1961.html

The New York Times (2007), Sweden Unzipped. http://travel.nytimes.com/2007/09/23/ travel/tmagazine/10well-goteborg-t.html

Go:teborg (s.d.), A Meetings and Events City. http://www.goteborg.com/en/Header/Meetings/About-Gothenburg/A-Meetings-andEvents-City/

\section{RESUMOS}

Como cidade portuária, Gotemburgo, na Suécia, tem-se transformado nas últimas décadas e considera-se actualmente uma cidade de eventos de sucesso e do conhecimento. Neste processo, a arte tem sido utilizada como um meio para criar uma cidade mais atractiva com um agradável ambiente para compras. Simultaneamente, a cidade registou graves problemas relacionados com a pobreza e com a segregação social e étnica. Neste artigo é analisada uma intervenção artística que tem como objectivo a utilização da cultura com vista ao alargamento e expansão do espaço público para além do espaço destinado ao consumo. A intervenção, denominada SpotCity, teve lugar em Brunnsparken, que é um parque de passagem localizado no coração de Gotemburgo. Em 2007, durante três semanas, o artista Tomas Ferm apropriou-se do parque entre eléctricos, autocarros e centros comerciais em Gotemburgo, transformando-o num centro cultural ao ar livre com um palco, um quiosque de arte e um contentor destinado à exibição de filmes. $O$ artigo analisa a forma como a SpotCity conseguiu usar a cultura para transformar momentaneamente um local estigmatizado num lugar de utopia.

As a port city, Gothenburg, Sweden, has been transformed throughout the last few decades and is currently considered a city of successful events and knowledge. Throughout this process, art has been used as a means to create a more attractive city with a congenial shopping environment. Simultaneously, the city has experienced major problems concerning poverty, and social and ethnic segregation. In this article, an artistic intervention with the objective of using culture to extend and expand public space beyond the area designated for consumption is analyzed. The intervention denominated SpotCity took place in Brunnsparken, which is a park located in the heart of Gothenburg. For three weeks in 2007, artist Tomas Ferm appropriated the park surrounded by trams, buses and shopping centers in Gothenburg, and transformed it into an outdoor cultural center with a stage, an art kiosk, and a structure designated for showing movies. The article analyzes how SpotCity managed to use culture in order to momentarily turn a stigmatized area into a utopia.

\section{ÍNDICE}

Keywords: public space, art, urban regeneration, post-politics, utopia

Palavras-chave: espaço público, arte, reabilitação urbana, pós-política, utopia 


\section{AUTORES}

\section{CATHARINA THÖRN}

Departamento de Ciências da Cultura, Universidade de Gotemburgo catharina.thorn@kultur.gu.se 